\title{
AVALIAÇÃO DE TECNOLOGIAS DE TRADUÇÃO PORTUGUÊS-LIBRAS VISANDO O USO NO ENSINO DE CRIANÇAS SURDAS
}

\author{
João Paulo Colling, UNIOESTE, joao.colling@outlook.com \\ Clodis Boscarioli, UNIOESTE, clodis.boscarioli@.unioeste.br
}

Resumo. No processo pedagógico a utilização de materiais que complementem o trabalho do professor e favoreçam o aprendizado do aluno é fundamental. As tecnologias têm inúmeras possibilidades de aplicações que podem e devem ser exploradas na educação em todos os níveis e para estudantes com diferentes necessidades, como no caso de crianças surdas. Este artigo aborda esta temática, avaliando a acessibilidade linguística em softwares educativos pela inserção de Libras, sua língua natural. Ao mesmo tempo, apresenta e discute as perspectivas desta inserção, ponderando e identificando os atributos necessários para realizar uma tradução efetivamente compreensiva para uma criança.

Palavras-chave: Acessibilidade, Crianças Surdas e Tecnologias Assistivas.

\section{EVALUATION OF TECHNOLOGIES IN PORTUGUESE-LIBRAS TRANSLATION IN PERSPECTIVE OF USE IN EDUCATION OF DEAF CHILDREN}

Abstract. In the pedagogical process the use of materials which complement the teacher's work and encourage the students learning is essential. The technology has innumerous potentials applications which can and should be explored in education at all levels and for students with different kinds of needs, as in the case of deaf children. This paper addresses this issue by evaluating the linguistic accessibility in educational softwares by insertion of Libras, their natural language. At the same time this paper presents and discusses the perspectives of this insertion, pondering and identifying the attributes necessary to make an effectively comprehensive translation for a child.

Keywords: Accessibility, Deaf Children and Assistive Technology.

\section{INTRODUÇÃO}

A educação na área da surdez é um assunto que vem sendo estudado por diversos especialistas ao longo da história, gerando várias vertentes e posições, principalmente em relação à criança, que sofre pelas limitações que lhe são impostas por sua deficiência. De acordo com Vigotsky (1997), o desenvolvimento da criança não se baseia apenas na idade, mas sim nas relações sociais do indivíduo mediadas por instrumentos e símbolos presentes em sua cultura. Atêm-se, portanto, em como utilizar este momento para alcançar o melhor aprendizado.

A apropriação de conhecimentos deve ser mediada pela língua e pela capacidade de comunicação, por vezes ausentes em crianças surdas ainda em apropriação da Libras (Língua Brasileira de Sinais). A língua pelo seu objetivo interpretativo torna-se então, fundamental para qualquer atividade ensino, já que se torna mediadora nesse processo. 
Há diferenças presentes entre a língua portuguesa e a Libras. A língua portuguesa é uma língua oral-auditiva que se baseia nos sons de forma linear, referências anafóricas contextualizadas e possui marcação de gênero. Tem como unidades mínimas os fonemas, a comunicação acontece pela produção sonora emitida pela boca, a recepção pelo ouvido e sua escrita é alfabética.

Segundo Quadros (2004), a Libras é uma língua visual-espacial, que possui suas particularidades de acordo com as experiências visuais da própria comunidade surda. Não é linear, podendo apresentar expressões faciais juntamente a uma configuração de mão, com referências anafóricas por meio do estabelecimento de pontos no espaço, não tem marcação de gênero. Tem como unidades mínimas as configurações de mão e a comunicação se dá pela emissão de sinais com as mãos, utilização do corpo, espaço e expressões faciais, com a recepção por meio visual.

Em relação às estruturas gramaticais o português apresenta-se mais rigoroso para a construção de uma frase, com uma sequência lógica de acordo com a fala. Já a Libras, que está totalmente desvinculada da língua oral, possui gramática e regras próprias, apresentando a forma com que a pessoa surda processa suas ideias.

Libras não tem uma equivalência evidente com português, mas uma construção gramatical própria e as tentativas de correspondência resultam no chamado português sinalizado ou bimodalismo. Este modelo, que se aproxima da transliteração de línguas é, há tempos, bastante refutado pela comunidade surda. A tentativa de utilizar a estrutura da língua portuguesa para apresentá-la em língua gestual acaba por não valorizar a Libras em sua estrutura própria, como também desestrutura o português, persistindo assim a defasagem em relação à leitura e escrita dos alunos (QUADROS, 1997).

A utilização de tecnologias assistivas vem ganhando destaque no ensino de crianças surdas pelos estímulos visuais que são oferecidos por recursos midiáticos, dentre eles vídeos, imagens, animações, entre outros. Portanto, a análise de ferramentas existentes faz-se necessária para avaliar sua aplicação no ensino, bem como de determinar atributos que possam ser melhorados - ou até adicionados - para a criação de uma nova ferramenta. Pretende-se, portanto, identificar atributos que devem estar presentes em um intérprete em formato digital direcionado a softwares educativos que sejam voltados ao ensino de crianças surdas.

A Seção 2 discute o uso das tecnologias como apoio às práticas pedagógicas no ensino de crianças surdas. A Seção 3 apresenta três softwares tradutores de português para Libras, apresentando elementos de estruturação da Libras. Na Seção 4 a avaliação realizadas e os resultados obtidos são apresentados. Por fim, a Seção 5 traz as considerações finais e perspectivas do trabalho.

\section{TECNOLOGIAS NO APOIO PEDAGÓGICO}

A barreira imposta pela ausência da audição somente é superada quando há compensação por outros sentidos. O processo de aprendizagem da criança surda está além da linguagem, recurso primário de comunicação e, portanto, também é passível de utilização de recursos gráficos e ilustrativos para a compreensão de conceitos.

A tecnologia pode ser utilizada para maximizar os resultados obtidos no processo educacional de indivíduos surdos, em especial, o ensino da língua portuguesa, Libras e consequentemente, na percepção de conceitos. Como exemplos de tecnologias elaboradas à comunidade surda, abaixo estão citados três softwares elaborados com o objetivo de inclusão digital da comunidade surda. 
O Dicionário da Língua Brasileira de Sinais (LIRA \& SOUZA, 2005), apresenta uma variedade de vocábulos com suas respectivas traduções em Libras, em ordem alfabética, por assunto ou então, classificados por configuração de mão. Nesse software é apresentado em cada vocábulo o seu significado, um exemplo de sua utilização em um contexto no português escrito, um na estrutura gramatical da Libras, um vídeo de sua tradução em Libras, sua classe gramatical, sua origem e, por fim, a configuração de mão utilizada para o sinal, como pode ser visualizado no exemplo ilustrado pela Figura $1^{1}$.

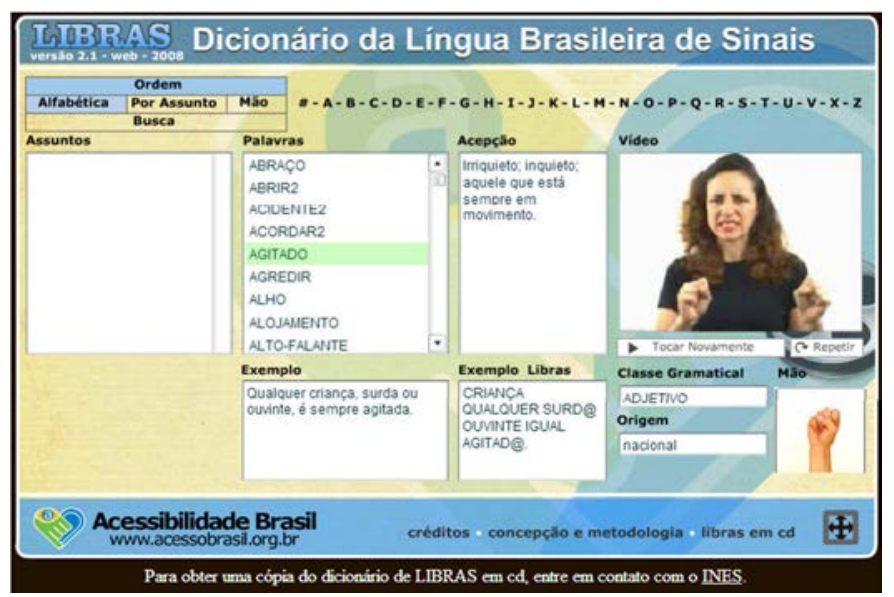

Figura 1: Tela de Tradução do Dicionário da Língua Brasileira de Sinais

O Multi-Trilhas (COUTO, 2008) é um jogo que busca atender surdos em processo inicial de aquisição de uma segunda língua, onde pode-se verificar verbos, substantivos, adjetivos e pronomes, apresentados em duas línguas: Libras, por meio de animações, e também em português escrito. A Figura 2 apresenta sua tela inicial.

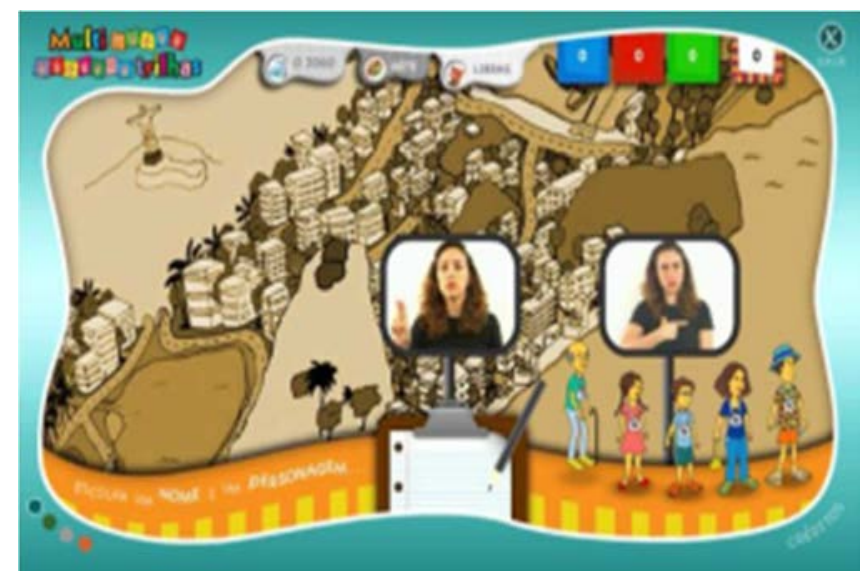

Figura 2: Tela Inicial do Jogo Multi-Trilhas

Libras Brincando e Aprendendo (LIBRASNET, 2010) é um jogo que objetiva passar conceitos ligados ao aprendizado nas disciplinas de Matemática, Ciências, Geografia e Português, adequadas às séries do ensino fundamental. Apresenta várias categorias, como Aulas, Ciências, Palavras Cruzadas e Geografia, onde o aluno pode escolher no menu qual deseja. Em cada uma destas categorias existem um ou mais cenários, sempre abordando o tema escolhido. Sua tela inicial está ilustrada na Figura 3.

\footnotetext{
${ }^{1}$ Todas as imagens dos softwares e avatares citados foram extraídas dos seus respectivos sites.
} 


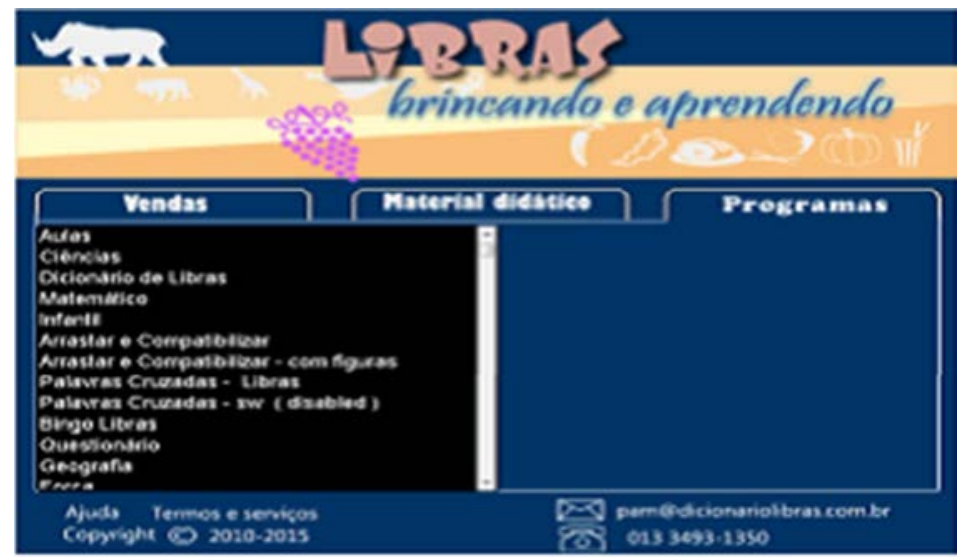

Figura 3: Tela Inicial do Jogo Libras: Brincando e Aprendendo

A grande questão que desafia esta área é, estão estes softwares realmente preparados para utilização no ensino de crianças surdas? Eles proporcionam interação auxiliada para efetiva compreensão de toda a interação?

Boscarioli et al. (2012) apresentam alguns os problemas de usabilidade nos dois jogos supracitados, apontando a necessidade de determinados recursos para a minimização das dificuldades encontradas em na interação. Das soluções apresentadas, destaca-se para ambos os jogos a incorporação de Libras em toda a interface, com descritores em todos os componentes por meio de recursos como imagens, vídeos e animações. Deste cenário, emerge a necessidade de avaliação dos tradutores de Português-Libras, para verificar sua incorporação em ferramentas de apoio ao ensino de surdos.

\section{SISTEMAS TRADUTORES DE PORTUGUÊS-LIBRAS}

Como visto, uma das necessidades de softwares voltados a deficientes auditivos é a acessibilidade proporcionada pela incorporação de Libras. Avaliações de softwares tradutores foram realizadas, com o objetivo de consolidar os atributos necessários para essa tradução. Os tradutores Português-Libras avaliados foram os softwares ProDeaf ${ }^{2}$, HandTalk $^{3}$ e Rybená ${ }^{4}$ (respectivamente apresentados na Figura 4), sendo o primeiro um tradutor de sites e os dois últimos aplicativos de dispositivos móveis.
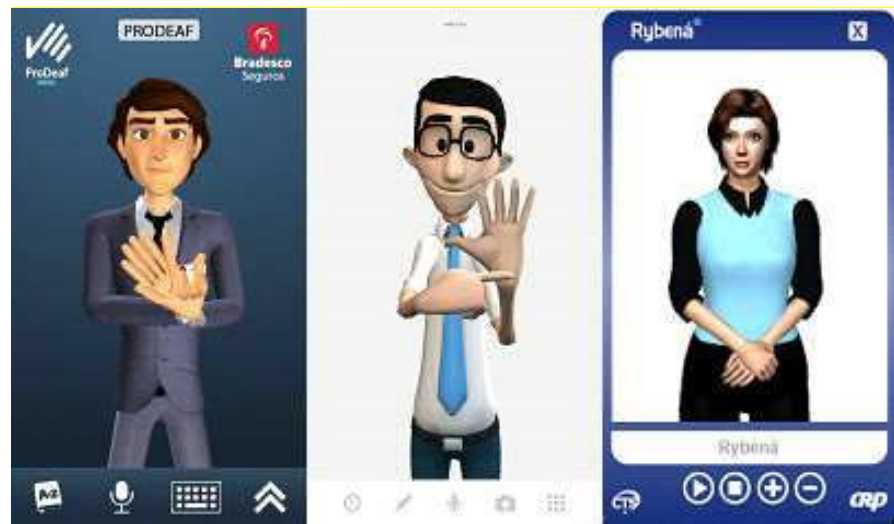

Figura 4: Softwares Tradutores de Português - Libras

\footnotetext{
${ }^{2}$ Disponível em: http://www.prodeaf.net/prodeaf-movel

${ }^{3}$ Disponível em: http://www.handtalk.me/app

${ }^{4}$ Disponível em: http://www.rybena.com.br/site-rybena/conheca-o-rybena/web

V. $12 \mathrm{~N}^{\circ}$ 2, dezembro, 2014
} 
As três ferramentas possuem outras variações de plataformas de execução das citadas anteriormente e possuem objetivos em comum, proporcionar acessibilidade, seja para auxiliar um atendimento a um cliente em um banco, facilitar a comunicação entre surdos e ouvintes no dia a dia, auxiliar a interação em sites, entre outras diversas aplicações.

$\mathrm{Na}$ tradução automática do português para Libras, os parâmetros da Libras devem ser incorporados nesses sistemas. Os parâmetros da língua surgiram com o estudo de diversos linguistas com o objetivo de oficializar a Libras e estruturá-la. Essa estrutura será utilizada de forma direta no neste trabalho, com os cinco parâmetros definidos pela língua, sendo eles, configuração de mãos, ponto de articulação, movimento, orientação de mão e expressões não manuais.

O primeiro fator a ser considerado é que as unidades básicas da língua portuguesa são os sons, responsáveis por diferenciar as palavras, e que para a Libras há o conceito de fonologia, denominada configuração de mão (CM). São atualmente 64 CM das quais 26 pertencem ao alfabeto manual (LIRA \& SOUZA, 2005).

Segundo Quadros \& Karnoop (2004), a CM é derivada a partir de dados coletados nas principais capitais brasileiras, agrupando de forma vertical de acordo com sua semelhança, representando, portanto, apenas manifestações de superfície da Libras.

A Orientação de Mão é a direção para qual aponta a palma da mão (QUADROS \& KARNOPP, 2004), pode ser determinada por direções: frente, trás, cima, baixo, lado esquerdo, lado direito e todas as suas diagonais.

Outro parâmetro a considerar é o do movimento, que apresenta uma variedade imensurável de possibilidades, e que se apresenta como um grande desafio. Dentre as características de movimento é possível destacar a classificação de movimentos internos da mão, movimentos de pulso e movimentos no espaço (QUADROS \& KARNOPP, 2004). A orientação da mão pode ser alterada durante a execução de um sinal.

Locação ou Ponto de Articulação é o local ou posição estabelecida para mão para a execução de um morfema, sendo o local definido por todos os pontos de alcance da mão (QUADROS \& KARNOPP, 2004). Como parâmetro da Libras inclui-se também as expressões não-manuais que englobam movimentos faciais, do olho, cabeça ou do tronco (QUADROS \& KARNOPP, 2004).

Uma avaliação com foco na capacidade de atendimento dos parâmetros da Libras com a participação de seis TILS (Tradutor e Intérprete da Língua de Sinais) foi realizada, e na sequência, uma avaliação com duas crianças surdas mediada por um TILS, que serão descritas na próxima seção.

\section{AVALIAÇÃO REALIZADA E ANÁLISE DOS RESULTADOS}

Ambas as avaliações feitas tiveram como base as traduções dos softwares com frases retiradas de um livro de língua portuguesa (BURANELLO \& REIS, 2007), do primeiro ano do ensino fundamental. Trata-se de frases pertencentes a histórias infantis, que é de comum utilização em aulas de Português, sendo um bom formato para avaliar a compreensão do usuário definido de acordo com a sinalização do avatar em Libras. As frases utilizadas estão apresentadas na sequência:

1) “...conseguiu colocar massa de pão e farinha branca..."

2) "Certo dia, ela precisou ir à floresta em busca de comida."

3) "Assustados, eles se esconderam pela casa."

4) "Os cabritinhos disseram que tomariam cuidado."

5) “...bastava observar suas patas pretas e sua voz rouca." 
6) “...voltavam da vila, onde foram prosear um pouco.”

7) “...no caminho, passaram em frente a uma casa.”

8) "Virgem santa, que pecado!"

9) “Aprender o quê, vô?”

10) "E continuaram no caminho, um pouco desconfiados."

Destas frases, foram selecionadas algumas palavras (em negrito) e avaliadas minuciosamente por especialistas (Tradutores e Intérpretes de Libras) para identificar quão precisa é a utilização dos parâmetros na execução dos softwares. Cabe ressaltar que os especialistas possuem aptidão na Libras utilizada localmente, com as variações linguísticas da cidade de Cascavel, no Paraná.

Os aplicativos foram apresentados para 6 TILS, e em seguida as frases foram executadas pelos softwares, uma de cada vez, e notas (de 1 a 5) eram atribuídas para cada parâmetro em cada sinal apresentado como tradução das palavras selecionadas. Apenas notas máximas dispensavam justificativa.

Também foi realizada outra avaliação, que consistiu em verificar a corretude das mesmas frases em contexto interpretativo pelo viés da criança surda. Os aplicativos foram apresentados a duas crianças surdas e foram executadas as frases, uma de cada vez. O aluno surdo apresentou as frases de acordo com o que entendeu e um TILS, que acompanhou a avaliação, transcreveu sua apresentação em português para posterior avaliação. Para o grau de entendimento foi atribuída uma nota de 1 a 5 , bem como identificados os principais erros que comprometeram sua compreensão. Alguns exemplos da interpretação das crianças podem ser verificados na Tabela 1.

Tabela 1: Frase 1 Interpretada pelas Crianças nos Softwares Tradutores

\begin{tabular}{|c|c|c|}
\hline $\begin{array}{c}\text { Frase Original: “...conseguiu } \\
\text { colocar massa de pão e } \\
\text { farinha branca...” }\end{array}$ & Criança A & Criança B \\
\hline Rybená & $\begin{array}{c}\text { “Minha mãe fez } \\
\text { massa de pão e farinha }\end{array}$ & $\begin{array}{c}\text { "Massa branca farinha fez } \\
\text { espera” }\end{array}$ \\
\hline HandTalk & $\begin{array}{l}\text { "colocou massa de } \\
\text { pão e trigo farinha } \\
\end{array}$ & $\begin{array}{c}\text { "Pão massa farinha } \\
\text { branca" }\end{array}$ \\
\hline ProDeaf & $\begin{array}{l}\text { "Mamãe fez farinha } \\
\text { rosca e leite” }\end{array}$ & “Passado vir pão” \\
\hline
\end{tabular}

Os resultados obtidos expressam a dificuldade de formalizar uma tradução coerente do português para Libras, considerando a diferença estrutural das línguas. Dentre os problemas encontrados, a maioria permeia a dificuldade em contextualizar todos os sinais na formação uma sentença compreensível, realizando a tradução efetiva da sentença e não sua transliteração (Português Sinalizado).

A avaliação foi obtida por meio da participação de seis TILS com diferenças em relação ao tempo de experiência na área. Os resultados obtidos exprimem dificuldade de formalização da língua, visto que há variação de opinião ente os intérpretes justificada pela sua interpretação e pela sua visão de grau de importância dos requisitos essenciais para formação de sinal. Além disto, deve-se considerar a apresentação dos sinais de acordo com a região, já que alguns sinais apresentados possam estar sinalizados corretamente, porém, não conferem com os utilizados na cidade de Cascavel, onde residem os participantes da pesquisa. 
Destas diversas opiniões extraem-se as principais dificuldades encontradas, de acordo com a sua recorrência. Os resultados podem ser mais bem observados na Figura 5, onde são apresentadas as porcentagens de conformidade para cada parâmetro com a comparação dos três softwares avaliados.

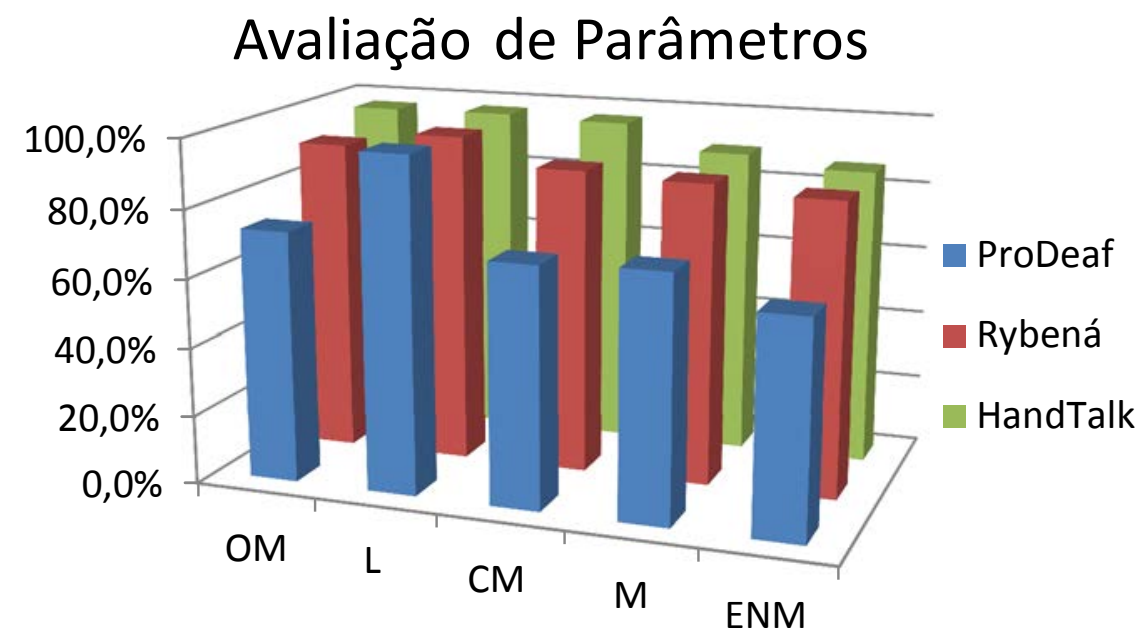

Figura 5: Resultados da Corretude dos Parâmetros da Libras para os Softwares Tradutores

As porcentagens refletem a sinalização errônea ou regionalizada em diversos casos, e a indiferença em muitos sinais na expressão do avatar, onde é apresentada sua principal falha. O desvio padrão significativo representa a não concordância de opiniões em relação a determinadas opiniões, porém o nível de corretude torna-se baixo devido as sinalizações incorretas. De outra forma, encontram-se problemas básicos de movimento em determinados casos e detalhes na configuração de mão que não conferem com as utilizadas nos sinais. Percebe-se, portanto a partir dos resultados, que o nível de corretude dos parâmetros apresenta-se alto, com exceções à sinalizações incorretas e regionalizadas como também a dificuldade de incorporar expressão ao sinais em que é necessária sua utilização.

Quanto à avaliação com as crianças os resultados expressam a dificuldade de compreensão das traduções geradas pelos softwares. A tradução do Rybená obteve uma compreensão das sentenças de aproximadamente 20\% para Criança A (CA) e $10 \%$ para Criança B (CB). Para a tradução realizada pelo HandTalk obteve-se resultados de compreensão de $30 \%$ para a CA e $17,5 \%$ para a CB. Por fim, para a tradução das sentenças do ProDeaf obteve-se resultado de 10\% para CA e de 2,5\% para a CB.

Esses resultados (Figura 6) mostram que esses softwares apresentaram baixo índice de entendimento devido ao formato de tradução estar mais associado ao português sinalizado que a Libras efetivamente. Os três apresentam uma estruturação da Libras provenientes da necessidade de tradução do português e esta associação deprecia as particularidades da Libras. Para uma tradução realmente efetiva, recomenda-se a estruturação inicial do intérprete digital de acordo com as particularidades da língua de sinais para posterior associação das sentenças em português. 


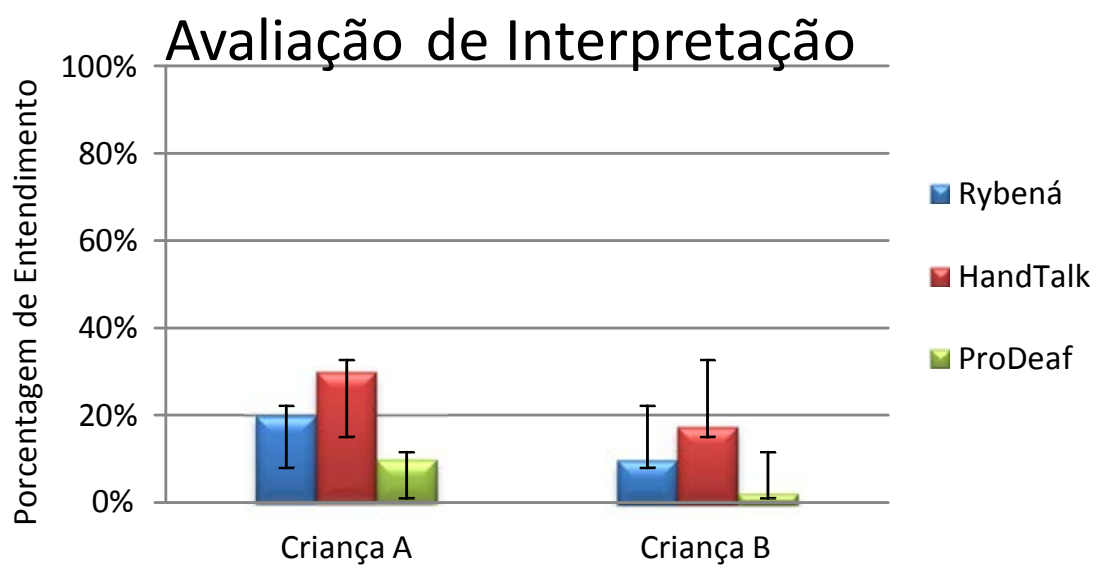

Figura 6: Resultados do Entendimento das Sentenças dos Softwares Tradutores

Cabe destacar que não há softwares criados voltados a crianças surdas em fase de aprendizagem. Estes softwares foram tomados como base para identificação dos parâmetros, e a pesquisa expõe as necessidades agregadas de acordo com o perfil com as opiniões dadas pelos TILS. Outra consideração, é que a soletração ou utilização de um sinal fora do contexto causa dificuldade na compreensão das sentenças de forma integral. As avaliações feitas relatam à compreensão das sentenças como um todo e, portanto, não representam diretamente qual parte da sentença que foi traduzida corretamente, mas sim, qual o nível de entendimento da criança em relação à frase.

\section{CONSIDERAÇÕES FINAIS}

Uma implementação de um avatar tradutor de Português-Libras deve, portanto, considerar diversos fatores para que a compreensão de uma sentença seja garantida. A sentença é formada por diversos morfemas, e estes devem estar dispostos não sequencialmente como são obtidos da língua portuguesa, mas com sua própria estrutura de acordo com a utilização comum da Libras.

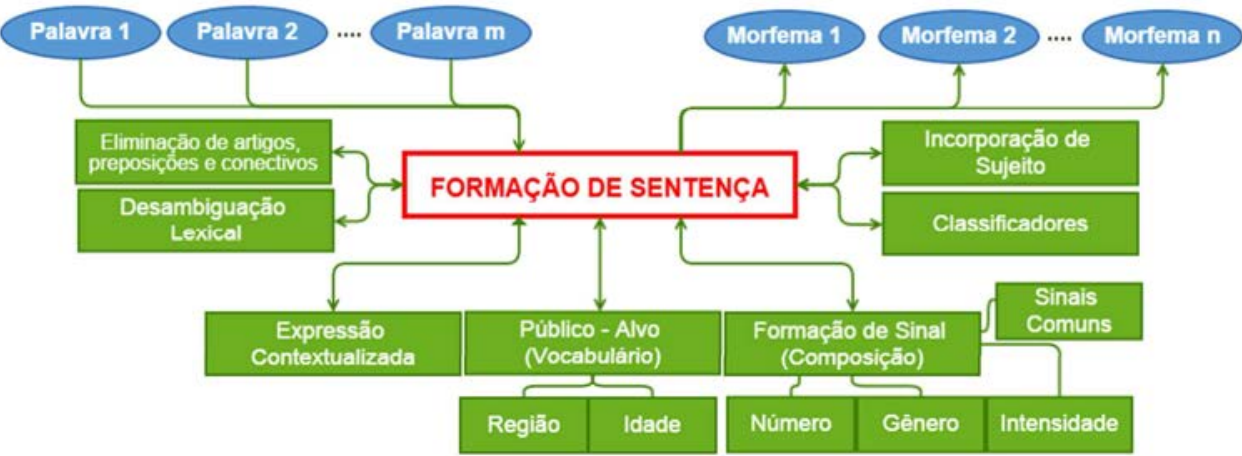

Figura 7: Processo de Tradução Português-Libras

A Figura 7 apresenta os fatores necessários para obter uma sinalização completa na tradução de sentenças em português. As sentenças sinalizadas que não incorporam estas considerações tornam-se português sinalizado. A formação das sentenças é realizada por $n$ morfemas provenientes do processamento de m palavras em português.

A composição da sentença se dá de forma bidirecional, ou seja, determinadas palavras podem exigir a utilização de mais de um atributo e por vezes um arranjo de palavras exigem determinados atributos. O atributo de eliminação de artigos, 
preposições e conectivos representa a necessidade de desestruturação gramatical da frase em português, uma vez que determinadas palavras não devem ser sinalizadas nas sentenças traduzidas em Libras.

Desambiguação lexical é um dos mais importantes e mais desafiadores pontos da tradução, considerando que os sinais devem ser sinalizados não de forma independente, mas de acordo com o contexto que atribuí um valor semântico que consequentemente deve ser utilizado para a apresentação do sinal correto.

A expressão contextualizada é a proposta de incorporar expressões que também acompanhem o contexto, que por vezes está desvinculada dos morfemas. A expressão também deve transmitir naturalidade na execução do sinal, fator que também facilita a compreensão das sentenças.

O público-alvo é um fator importante na definição do avatar, visto que o domínio e apresentação dos sinais diferem conforme a aplicação. Os principais classificadores de público-alvo são idade e região. Pela idade pode-se nivelar o vocabulário utilizado, verificando se o mesmo é acessível ao seu contexto de ensino o que reflete em agregar facilitadores ou descritores à tradução quando o vocábulo não é utilizado em seu contexto.

Existem padronizações nacionais da língua como Capovilla \& Raphael (2001) que podem ser adequadas juntamente com as características regionais para atingir uma melhor adaptação a um público-alvo maior. Caso a necessidade aplica-se ao ensino da língua regional, vale-se dos vocábulos utilizados na região.

A formação de sinais remete ao processo de obter um sinal a partir de dois outros sinais, em vezes dois morfemas que representam uma palavra (gênero e sinais simples) ou então um morfema que incorpora mais de uma palavra (número e intensidade). As vias de composição por número, gênero e intensidade são propriamente a incorporação de suas classificações ao sinal. A composição de sinais simples incorporam dois sinais que apresentados em sequência possuem potencial semântico de outra palavra (Ex.: Casa + Cruz = Igreja).

Também se encontra como desafio a identificação e utilização de classificadores, para sinais que precisam da incorporação de um movimento não nativo para representar um algo de forma completa, como a representação de uma ação, a descrição de uma forma, entre outros.

Incorporação de sujeito em frases que possuem sujeitos ocultos é um complemento que pode atribuir melhor explicação do que representa a sentença em si, visto que a sinalização pode concretizar quem é o sujeito que está realizando a ação. Além destas considerações é preciso ressaltar que a precisão dos parâmetros da Libras na apresentação dos sinais é de suma importância para que os morfemas individualmente também possam ser identificados e compreendidos.

Finalmente, é preciso observar que a formalização de Libras não é precisa, e que há diversas vertentes dela pela sua flexibilidade. Dado a necessidade trivial de tornar acessível um software educacional, a incorporação de Libras deve ser realizada de forma precisa e de acordo com a necessidade das aplicações em geral sugere-se incorporação da Libras estática com sinais bem definidos. A incorporação de Libras deve auxiliar realmente na compreensão e interação dos usuários, facilitando o processo de ensino-aprendizagem.

A partir desta pesquisa é possível iniciar o desenvolvimento e estruturação de cada um dos módulos para um tradutor Português-Libras, visto que uma visão macro das necessidades deste tipo de software foi apresentada, e que estas precisam ser investigadas a fundo para obtenção de resultados que atinjam a tradução com um alto nível de corretude para a compreensão de crianças. 
Referências

BOSCARIOLI, C., BAQUETA, J. J., COLLING, J. P., SALLES, C. G. Investigando a Usabilidade em Jogos Educacionais Baseados em Imagens e Vídeos para o Ensino de Crianças Surdas. In: Congresso Brasileiro de Educação Especial (CBEE), São Carlos, 2012.

BURANELLO, C.; REIS, E. V. dos. Língua Portuguesa, 1ª Série : Manual do Professor. São Paulo: Escala Educacional, 2005.

CAPOVILLA, F. C.; RAPHAEL, W. D. Dicionário enciclopédico ilustrado trilíngüe da língua brasileira de sinais. São Paulo: Editora da Universidade de São Paulo, Impressão Oficial do Estado, 2001.

COUTO, R. M. S. Processo de Projeto do Jogo Multi-Trilhas: Um exemplo de Design Participativo. In: $8^{\text {a }}$ Congresso Brasileiro de Pesquisadores e Desenvolvimento em Design. São Paulo, 2008. p. 4107 - 4111.

LIRA, G. A.; SOUZA, T. A. F. Dicionário da Língua Brasileira de Sinais, 2005. Disponível em: <http://www.acessobrasil.org.br/libras/>. Acesso em 15 de jul de 2014. LIBRASNET. Libras: Brincando e Aprendendo, 2010. Disponível em: http://www.librasnet.com.br/shockwave/menu/menu.htm. Acesso em: 15 jul. 2014.

PRODEAF Tecnologias Assistivas. Soluções. 2014. Disponível em http://www.prodeaf.net/. Acesso em: 25 mar. 2014.

QUADROS, R. M. Educação de surdos: a aquisição da linguagem. Porto Alegre: Artes Médicas. 1997. RAMSEY, Claire L. Deaf children in public schools: placement, context and Consequences. [s.l]: Gallaudet University Press 1997

QUADROS, R. M.; KARNOPP, L. Língua Brasileira de Sinais: Estudos Línguísticos, Porto Alegre: Artes Médicas, 2004.

ICTS. Projeto Rybena. Disponível em: < http://www.grupoicts.com.br/ > . Acesso em: 25 mar. 2014.

VYGOTSKY, L. S. Obras escogidas: fundamentos de defectología. Tomo V. Madrid: Visor, 1997.

ZERO PIXEL. Hand Talk, 2012. Disponível em: http://www.handtalk.com.br/. Acesso em: 25 mar. 2014. 